\title{
Corrosion Properties of CrAlN and TiAlN Coatings Deposited by Thermoreactive Deposition Process
}

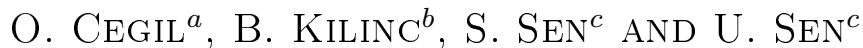 \\ ${ }^{a}$ Korfez Technical and Industrial Vocational High School, Department of Metal Technology \\ 41780, Korfez/Kocaeli, Turkey \\ ${ }^{b}$ Department of Metallurgical and Materials Engineering, Institute of Arts and Sciences, Sakarya University \\ Esentepe Campus, 54187 Sakarya, Turkey \\ ${ }^{c}$ Department of Metallurgical and Materials Engineering, Engineering Faculty, Sakarya University \\ Esentepe Campus, 54187 Sakarya, Turkey
}

\begin{abstract}
In the present study, the corrosion behaviors of chromium aluminum nitride ( $\mathrm{CrAlN})$ and titanium aluminum nitride (TiAlN) coatings deposited on AISI D2 steel samples are reported. Steel samples were pre-nitrided at $575^{\circ} \mathrm{C}$ for $8 \mathrm{~h}$ in the first step of the coating process, and then TiAlN and CrAlN coatings were performed by thermoreactive deposition process in a powder mixture consisting of alumina, ammonium chloride, aluminum and ferrous titanium or ferrous chromium for TiAlN or CrAlN, respectively. Coating treatments were realized at $1000{ }^{\circ} \mathrm{C}$ for $2 \mathrm{~h}$. Coated samples were characterized by X-ray diffraction analysis, optical microscopy, scanning electron microscopy, and microhardness tester. The corrosion properties of uncoated and coated samples were characterized by potentiostatic polarization test. CrAlN and TiAlN coated steel specimens exhibited the higher corrosion resistance than uncoated steels in a $0.5 \mathrm{M} \mathrm{NaCl}$ solution.
\end{abstract}

DOI: 10.12693/APhysPolA.125.359

PACS: 82.45.Bb, 81.65.Kn, 81.15.-z

\section{Introduction}

Coatings provide a way of extending the limits of the use of the materials at the upper end of their performance capabilities, by allowing the mechanical properties of the substrate materials to be maintained while protecting against wear, oxidation, and corrosion. In many applications, the coated parts are frequently exposed to an aggressive working environment, for instance, a $\mathrm{Cl}^{-}$ containing corrosive medium which has strong effects in promoting localized corrosion [1]. For the fabricated hard coating, two kinds of thin hard coating processes, which are CVD and PVD, have been put into practical application in worldwide industries [2-5]. The third one is the thermoreactive deposition (TRD) technique, which can be applied for carbide, nitride, or boride type hard coating on iron-based hard coating alloys. Reaction diffusion laws govern the formation and the growth of intermetallic layers at the interface between solid and treatment bath in the thermochemical coating treatment [6].

Most transition metals form binary or ternary nitrides, with good mechanical, tribological, anticorrosive, and biocompatibility properties. However, binary materials only give a partial response to the growing need to obtain materials with better properties and greater mechanical performance. The best example for the enhancement of the properties by the inclusion of a third component is titanium aluminum nitride. Titanium nitride (TiN) and titanium aluminum nitride coatings have been applied to tools, dies, and many mechanical parts to increase their lifetime and performance owing to their attractive properties such as high hardness, good thermal stability and oxidation resistance, good wear, and chemical stability [7]. Chromium nitride $(\mathrm{CrN})$ based multicomponent nitride is a typical example. Similar to TiN, CrN has been successfully applied to the molding dies, wear components, and cutting tools. CrN is known to be superior to TiN in corrosion and wear resistances, friction behaviour, and toughness [8]. Similar to the TiAlN coating system, the incorporation of $\mathrm{Al}$ into the cubic $\mathrm{CrN}$ crystalline structure greatly enhances the hardness of the chromium aluminum nitride coating system [9]. In this work, TiAlN and CrAlN coatings were deposited on AISI D2 steel by TRD. The corrosion behaviour of the deposited coatings and substrate in a $0.5 \mathrm{M} \mathrm{NaCl}$ solution was tested and compared by an electrochemical method.

\section{Experimental procedures}

Titanium aluminum nitride and chromium aluminum nitride coating was performed on pre-nitrided AISI D2 steel with initial hardness value of $550 \pm 80 \mathrm{HV}$ and consisting of $1.54 \% \mathrm{C}, 0.28 \% \mathrm{Si}, 0.29 \% \mathrm{Mn}, 0.023 \% \mathrm{P}$, $0.005 \% \mathrm{~S}, 11.3 \% \mathrm{Cr}, 0.74 \% \mathrm{Mo}, 0.77 \% \mathrm{Ni}, 0.74 \% \mathrm{~V}$, and iron (balance). Prior to nitriding, all the samples were prepared metallographically by grinding with a 1200 grid emery paper and polished by $1 \mu \mathrm{m}$ alumina paste in the final stage. The preparation of the substrates for the process consisted of ultrasonic aided cleaning with acetone and ethyl alcohol. The pre-nitriding treatment was carried out in nitrogen and ammonia atmosphere at $575^{\circ} \mathrm{C}$ for $8 \mathrm{~h}$. TiAlN and CrAlN coatings treatment were performed on the pre-nitrided steel by TRD in the alumina crucible at $1000^{\circ} \mathrm{C}$ for $2 \mathrm{~h}$ for disk materials whose pack consists of ferro-titanium (for TiAlN), ferro-chromium (for CrAlN), aluminium, ammonium chloride and alumina. Alumina crucible was sealed with an alu- 
mina lid and alumina-based cement. Characterization of nitro-titanized AISI D2 steel was carried out by using following devices and methods.

Cross-sections of coated steels were prepared metallographically to observe morphological details using Nikon Eclipse L150 microscope and JEOL JSM-6060 LV scanning electron microscope. XRD analysis was performed on the sample surface. $\mathrm{Cu} K_{\alpha}$ radiation with a wavelength of $1.5418 \AA$ was used. The thickness of TiAlN and CrAIN layers formed on AISI D2 steel was measured by an optical micrometer attached to the optical microscope. The hardness of the coating layers and substrates was measured on the cross-sections using Future Tech FM 700 Vickers indenter with 5 g loads and during $5 \mathrm{~s}$.

Corrosion behaviour of uncoated, TiAlN coated and CrAIN coated samples AISI D2 tool steels were examined in the aerated $0.5 \mathrm{M} \mathrm{NaCl}$ solution $\mathrm{pH}$ values of which is 5.96. Reagent grade chemicals and doubly distilled water were used for the solution preparation, and the tests were carried out at room temperature and open-air conditions. The traditional three-electrode system was applied, where in the saturated calomel electrode (SCE) acted as a reference electrode and a graphite bar as a counter electrode. The polarization curves were measured at a scan rate of $1 \mathrm{mV} / \mathrm{s}$, starting from an initial potential of $-0.1 \mathrm{~V}$ vs. the open circuit potential of the tested samples. Corrosion potential $\left(E_{\text {corr }}\right)$, corrosion current $\left(I_{\text {corr }}\right)$, anodic Tafel slope $\left(\beta_{\mathrm{a}}\right)$, cathodic Tafel slope $\left(\beta_{\mathrm{c}}\right)$ were provided after analyzing by that software.

\section{Results and discussion}

The TiAlN and CrAlN coatings have been produced successfully by thermoreactive diffusion technique on AISI D2 steel. The cross-sectional optic micrographs of the coatings are demonstrated in Fig. 1. As shown from this figure, the coating layers are compact homogeneous, with significant regularities in their thickness, and presenting a smooth interface with the substrate. The coating thicknesses of TiAlN and CrAlN are $7.89 \pm 0.34 \mu \mathrm{m}$ and $11.8 \pm 1.3 \mu \mathrm{m}$, respectively. XRD analysis of the TiAlN and CrAlN coated AISI D2 steel samples at $1000^{\circ} \mathrm{C}$ for $2 \mathrm{~h}$ showed that the phases formed in the TiAlN and CrAlN coating layer were TiN, $\mathrm{Ti}_{3} \mathrm{AlN}$ and $\mathrm{Ti}_{3} \mathrm{Al}_{2} \mathrm{~N}_{2}$, and $\mathrm{Cr}_{2} \mathrm{~N},(\mathrm{Cr}, \mathrm{Fe})_{2} \mathrm{~N}_{1-x}, \mathrm{AlN}$, $\mathrm{Fe}_{2} \mathrm{~N}$, respectively. The hardness of coating layers is much higher than that of the steel matrix $(550 \pm 80 \mathrm{HV})$ because of the presence of hard nitride phases [10,11]. In particular, TiAlN coating showed higher hardness value $\left(2251 \pm 255 \mathrm{HV}_{0.005}\right)$ than CrAlN $\left(2067 \pm 160 \mathrm{HV}_{0.005}\right)$ coating [12].

The corrosion potential $\left(E_{\text {corr }}\right)$, current density $\left(I_{\text {corr }}\right)$ and polarization resistance $\left(R_{\mathrm{p}}\right)$ obtained by Tafel calculations for uncoated, TiAlN and CrAlN coated steels are given in Table. Figure 2 shows the potentiodynamic polarization curves of the uncoated, TiAlN and CrAlN coated AISI D2 steels tested in the $0.5 \mathrm{M} \mathrm{NaCl}$ aqueous solution. The corrosion current density and the corrosion

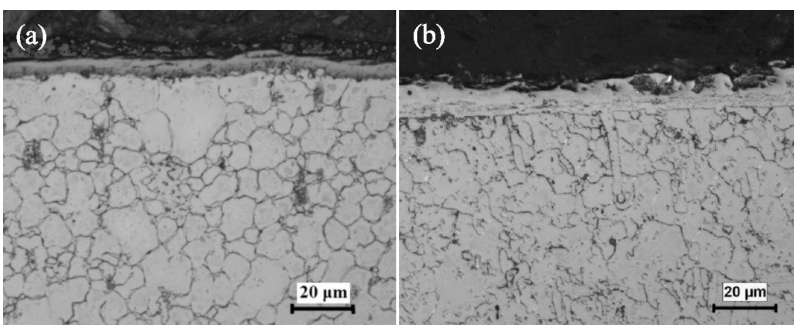

Fig. 1. Microstructure of experimental material (a) TiAlN and (b) CrAlN coated AISI D2 steel.
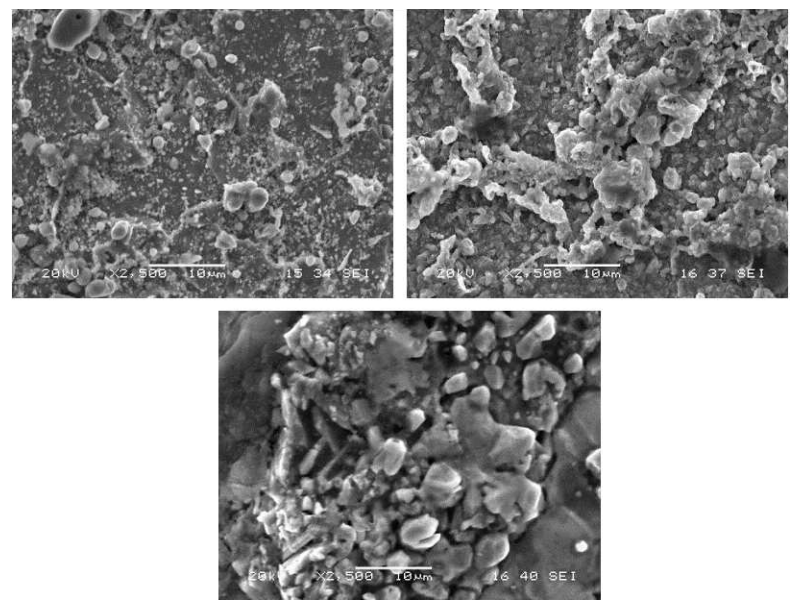

Fig. 2. The potentiodynamic polarization curves of the uncoated, TiAlN and CrAlN coated AISI D2 steels.

TABLE I

Potentiodynamic polarization parameters of uncoated, TiAlN coated and CrAlN coated AISI D2 steels in a $0.5 \mathrm{M} \mathrm{NaCl}$ solution.

\begin{tabular}{c|c|c|c|c|c}
\hline \hline AISI D2 & $\begin{array}{c}I_{\text {corr }} \\
{\left[\mu \mathrm{A} / \mathrm{cm}^{2}\right]}\end{array}$ & $\begin{array}{c}E_{\text {corr }} \\
{[\mathrm{mV}]}\end{array}$ & $\begin{array}{c}B_{\mathrm{a}} \\
{[\mu \mathrm{V}]}\end{array}$ & $\begin{array}{c}\beta_{\mathrm{c}} \\
{[\mu \mathrm{V}]}\end{array}$ & $\begin{array}{c}R_{\mathrm{p}} \\
{\left[\Omega / \mathrm{cm}^{2}\right]}\end{array}$ \\
\hline uncoated & 341.56 & -857 & 693 & 418 & 0.3314 \\
TiAlN coated & 6.12 & -516 & 478 & 623 & 19.1714 \\
CrAlN coated & 3.57 & -509 & 379 & 166 & 14.023
\end{tabular}

potential were obtained by the intersection of the extrapolation of anodic and cathodic Tafel curves. The corrosion current densities of the coatings were found much lower than that of the substrate steel. The corrosion behaviour of TiAlN and CrAlN may also have been affected because of the presence of $\mathrm{Al}$. It has been reported that the addition of $\mathrm{Al}$ to the transition metal nitrides improves the corrosion resistance [13-16].

The polarization resistance $\left(R_{\mathrm{p}}\right)$ of a metal is the slope of the potential-current density $(\Delta E / \Delta I)$ plot at the free-corrosion potential. The polarization resistance is related to the corrosion current, $I_{\text {corr }}$, through the SternGeary equation (Eq. (1)) [17]:

$$
\frac{\Delta E}{\Delta I}=\frac{\beta_{\mathrm{a}} \beta_{\mathrm{c}}}{2.3 I_{\mathrm{corr}}\left(\beta_{\mathrm{a}}+\beta_{\mathrm{c}}\right)} \text {. }
$$


Potential polarization curves of the TiAlN and CrAlN coated samples include an evident passive stage. The existence of the passive region is due to the spontaneous formation of a thin oxide passive layer on the external surface when the coating is contacting the $\mathrm{NaCl}$ solution. This passive oxide layer eliminates localized corrosion and protects the steel substrate from degradation at the pinholes [8, 18]. As shown in Fig. 2, the CrAlN coated sample has got the highest $E_{\text {corr }}$ value which is coming upon the upper site of passive region of the uncoated and TiAlN coated AISI D2 steels, and current density of the CrAlN coated steel is lower than that of the uncoated and TiAlN coated steels. These electrochemical characteristics demonstrated the capacity of the TiAlN and $\mathrm{CrAlN}$ coating for providing corrosion protection to the underlying substrate $[19,20]$.

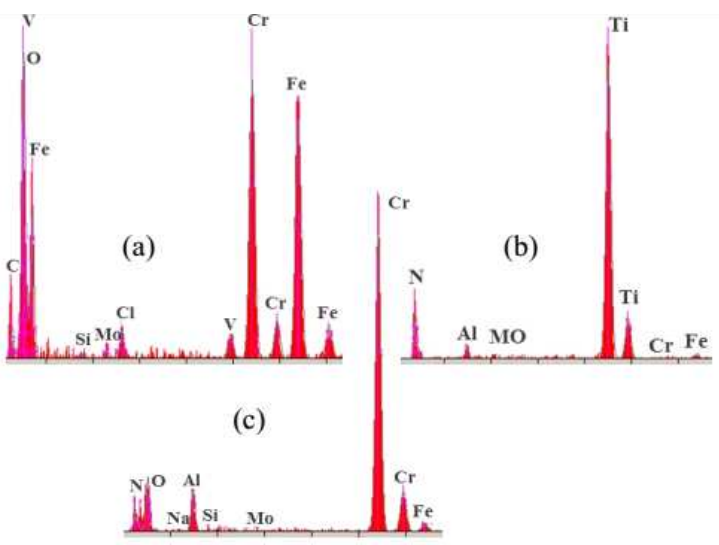

Fig. 3. Scanning electron micrographs and EDS analysis of the uncoated (a), TiAlN coated (b), and CrAlN coated specimens.

Scanning electron micrographs (SEM) along with energy dispersive X-ray spectroscopy (EDS) analysis for TiAlN and CrAlN coatings are shown in Fig. 3. In case of TiAlN coating, the EDS point analysis (Fig. 3b) shows the presence of $\mathrm{Ti}(75.91 \%)$ as the main phase along with $\mathrm{Al}(2.2 \%)$ and $\mathrm{N}(19.88 \%)$. A very small amount of Mo, $\mathrm{Fe}, \mathrm{Cr}$ is present, which may be due to the micro voids or pores present in the coating. Further in case of CrAlN coating, $\mathrm{Cr}(67.06 \%)$ and $\mathrm{Al}(5.99 \%)$ are the main phases along with $\mathrm{N}(12.01)$ and $\mathrm{O}(11.23 \%)$, as indicated by the EDS analysis (Fig. 3c). As shown from the EDS analysis, the elements of $\mathrm{Al}, \mathrm{N}$, and Ti for TiAlN coating and $\mathrm{Al}, \mathrm{N}$ and $\mathrm{Cr}$ for $\mathrm{CrAlN}$ coating were detected on the corroded coated steel surfaces. These results show that the coatings layers formed on the steel sample withstand during the corrosion test.

\section{Conclusions}

The TiAlN and CrAlN coatings were deposited successfully on AISI D2 tool steel by using TRD technique.
The phases formed in the TiAlN and CrAlN coating layer were $\mathrm{TiN}, \mathrm{Ti}_{3} \mathrm{AlN}, \mathrm{Ti}_{3} \mathrm{Al}_{2} \mathrm{~N}_{2}$ and $\mathrm{Cr}_{2} \mathrm{~N},(\mathrm{Cr}, \mathrm{Fe})_{2} \mathrm{~N}_{1-x}$, $\mathrm{AlN}, \mathrm{Fe}_{2} \mathrm{~N}$ phases, respectively. The hardness of coating layers is much higher than that of the steel matrix $(550 \pm 80 \mathrm{HV})$ because of the presence of hard nitride phases. The corrosion current densities of the TiAlN and $\mathrm{CrAlN}$ coatings in an aerated $0.5 \mathrm{M} \mathrm{NaCl}$ solution at room temperature were found much lower than that of the substrate steel.

\section{References}

[1] V. Chawla, A. Chawla, Y. Mehta, D. Puri, S. Prakash, B.S. Sidhu, J. Austral. Ceram. Soc. 47, 48 (2011).

[2] M. Hagarova, J. Savkova, D. Jakubeczkova, J. Metals, Mater. Miner. 18, 25 (2008).

[3] M.A. Khafri, F. Fazlalipour, J. Phys. Chem. Solids 69, 2465 (2008).

[4] M. Adamiak, L.A. Dobrzanski, Appl. Surf. Sci. 254, 4552 (2008).

[5] D. Bonacchi, G. Rizzi, U. Bardi, A. Scrivani, Surf. Coat. Technol. 165, 35 (2003).

[6] S. Sen, Vacuum 79, 63 (2005).

[7] O. Cegil, B. Kılınc, U. Sen, S. Sen, in: IMMC'16 Metallugy \& Materials Congress, Istanbul (Turkey), Eds.: A.F. Dericioglu, K. Kazmanli, S. Timur, C. Durucan, H. Savaş, UCTEA Chamber Of Metallurgical Engineers, Istanbul 2012, pp. 453.

[8] X. Ding, A.L.K. Tan, X.T. Zeng, C. Wang, T. Yue, C.Q. Sun, Thin Solid Films 516, 5716 (2008).

[9] Y.C. Chim, X.Z. Ding, X.T. Zeng, S. Zhang, J. Thin Solid Films 517, 4845 (2009).

[10] P.H. Mayrhofer, D. Music, J.M. Schneider, J. Appl. Phys. 100, 094906 (2006).

[11] R. Hauert, J. Patscheider, Adv. Eng. Mater. 2, 247 (2000).

[12] V. Chawla, J. Mater. Sci. Eng. A 3, 22 (2013).

[13] H. Lee, S.H. Ahn, J.G. Kim, Surf. Coat. Technol. 190, 417 (2005).

[14] T.M. Brizuel, G.A. Luisa, I. Braceras, J.I. Onate, S.J.C. Lopez, M.D. Martine, L.C. Cartes, A. Fernandez, Surf. Coat. Technol. 200, 192 (2005).

[15] S.R. Pulugurtha, D.G. Bhat, M.H. Gordon, J. Shultz, M. Staia, S.V. Joshi, S. Govindarajan, Surf. Coat. Technol. 202, 1160 (2007).

[16] V. Chawla, A. Chawla, B.S. Sidhu, S. Prakash, D. Puri, J. Miner. Mater. Character. Eng. 9, 1037 (2010).

[17] V.S. Sastri, Green Corrosion Inhibitors, Wiley, New Jersey 2011, pp.72.

[18] O. Cegil, Ph.D. Thesis, Sakarya University, 2012.

[19] O. Cegil, U. Sen, S. Sen, Acta Phys. Pol. A 123, 265 (2013).

[20] O.M.S. Quinter, W.A. Chaparro, L. Ipaz, J.E.S. Barco, F.E. Beltran, G. Zambrano, Mater. Res. 16, 204 (2013). 